\title{
Stress Concentration Analysis of the Injection Pump Shaft
}

\author{
Paweł Bałon ${ }^{1,2^{*}}$, Andrzej Świątoniowski², Edward Rejman³ ${ }^{3}$ Bartłomiej Kiełbasa1', \\ Robert Smusz ${ }^{3}$, Janusz Szostak², Łukasz Kowalski²
}

1 ZPU Mirosław Pogoda, ul. Wojska Polskiego 3, 39-300 Mielec, Poland

2 AGH University of Science and Technology, Al. Mickiewicza 30-B2, 30-059 Kraków, Poland

3 Rzeszów University of Technology, Al. Powstańców Warszawy 12, 35-959 Rzeszów, Poland

* Corresponding author's e-mail: p.balon@szel-tech.pl

\begin{abstract}
The paper presents the methodology for designing the injection shaft drive for diesel engines with 2,3,4,6 and 8 cylinders as well as power from 2.5 to $52 \mathrm{~kW}$ per cylinder using the FEM method and experimental research. The pump is the original solution of the authors. The shaft is a basic part of the pump with a complex structure. In order to assess the state of stress in the shaft, the FEM analytical method was used and experimental tests were carried out, subjecting the shaft to torsional moment resulting from the transmitted power. Experimental studies confirmed the results of numerical calculations and the correctness of the adopted solution. The destructive tests were carried out to assess the maximum load capacity of the shaft, loading it with an increasing torque until visible plastic deformations occurred. This condition appeared at twice the moment $(\mathrm{Ms}=602 \mathrm{Nm})$ in relation to the maximum predicted moment in operation (extreme operating conditions of the pump shaft). The theoretical studies confirmed very significant stress concentration ( $\alpha \mathrm{k}$ coefficient at the level of 2.63 or even 4.7 ), which may be the cause of fatigue cracks. It also determines the strength of the shaft and its torsional stiffness, which influences the proper functioning of the pump and ensures adequate fuel injection phases.
\end{abstract}

Keywords: pump shaft, diesel engine, FEM analysis, torque, torsion, pump drive shaft

\section{INTRODUCTION}

In order to assess the suitability and functionality of a new type of pump, a prototype was developed and subjected to stand tests. Our own experience in designing, the results of stand tests, and an assessment of pump durability based on many years of their use indicate that one of the critical parts is the drive shaft. This element works under highly difficult conditions, where it is subjected primarily to the torque of various levels. This affects the way in which it breaks, which typically takes the form of fatigue destruction. If such destruction occurs during pump use, it causes irreversible damage to its structure, resulting in the subsequent destruction of many of the pumps' critical elements. Designers are required to meet many requirements when designing machine elements, including the provision of appropriate structural, operational and technological features and specifications. Therefore, it is necessary to carry out model and experimental studies at the design stage in order to shorten the construction process and reduce the costs involved.

\section{MODEL RESEARCH}

The solution adopted assumes that the drive shaft will be composed of two parts: an actual shaft and a shrink-fitted ring controlling rotor pistons which move the fuel feed piston (Fig.1). Due to the existing loads as well as the manufacturing technology, C25 steel was applied in a thermally improved state, with a hardness of around HB 250. The adopted design of the pump forced the introduction of elements into the shaft structure, which will cause stress concentration, 


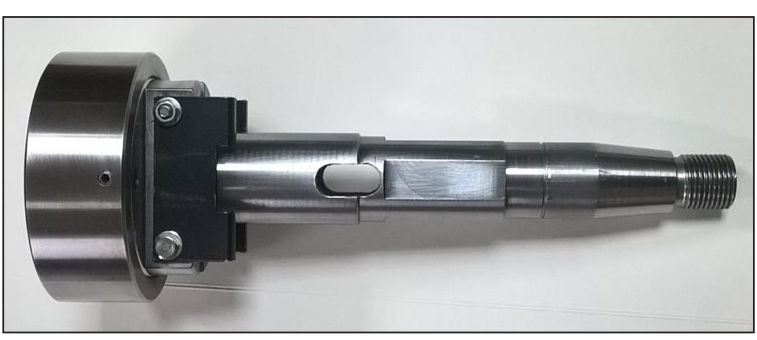

Fig. 1. Photo of the pump drive shaft

and thus a potential source for fatigue cracking. The focal point is a bean cutout with a width of $10 \mathrm{~mm}$ and a length of $20 \mathrm{~mm}$, and an annular notch around it with diameters of 25 and $28 \mathrm{~mm}$ (Fig. 2). These areas were rated specifically, taking into consideration stress concentration as a potential area of destruction.

This report presents the results of numerical, analytical and experimental strength testing of the high pressure injection pump's drive shaft subjected to torsion. The numerical analysis focuses on the analysis of stress concentration areas which result from the existence of the notches. Several variants of undercut machining have been analyzed for stepped shafts. Analytical considerations included determination of shape coefficients in areas with significant geometric notch existence. In turn, in experimental studies, the focus was on determining the maximum strength of the shaft exposed to the twisting moment. Formulas of particular materials strength for a given cross- section were used for the practical design of the shaft in the initial phase. It was assumed that the shaft is loaded with a twisting moment $\mathrm{M}_{\mathrm{s}}$ $=300 \mathrm{Nm}$ applied to the conical surface of the input part and spread evenly. For this load state, the maximum shear stresses reach a value of $\tau_{\max }=$ 105.10 MPa. The multiple notches present in this design are a non -standard solution and it is difficult to find such a case in the literature, wherein the local stress concentration is described in an analytical or graphic way $[7,8]$. These notches interact with each other [5]. Therefore, experimental, analytical, and numerical stress concentration studies were necessary. In order to estimate the occurrence of stress concentration at critical points along the shaft, numerical tests were first carried out using the finite element method. The commercial software COMSOL Multiphysics was used for the numerical calculations. For this purpose, a 3D model of the shaft was created, loading it with an evenly distributed twisting moment with a value of $\mathrm{M}_{\mathrm{s}}=300 \mathrm{Nm}$ applied to a conical

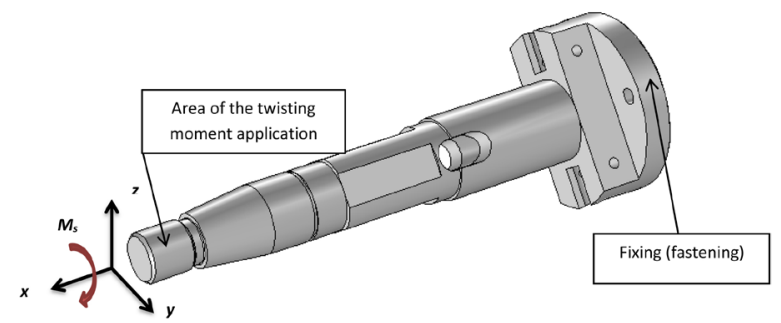

Fig. 2. Front view of the shaft

surface (Fig. 2). The model of a linear resilient material with the Young's modulus equal to $\mathrm{E}=$ $200 \mathrm{GPa}$, the Poisson coefficient $\mathrm{n}=0.33$ and a yield strength of $\mathrm{Re}=320 \mathrm{MPa}$ (steel $1.0406 \mathrm{EN}$ 10083-2) was assumed. Stress was determined based on the Huber-von Mises-Hencky hypothesis (H-M-H). In the discrete model a grid of tetrahedral finite elements of the tetra type was used, see Figure 6.

Results of the initial calculations are shown in the figures below. Figure 3 and Figure 4 show the global distribution of stresses reduced in the shaft. As can be seen, there are two zones, A and $\mathrm{B}$, where there is a large concentration of stresses connected with the occurrence of significant geometric notches. On this basis, it can be estimated that the maximum stresses occur in zone B and, consequently, this structural detail is focused on in later considerations. Stress analysis according to Figure $4 \mathrm{~B}$ shows that the highest stresses occur in the bean hole and cross-section of rolls with a diameter of 28 to $25 \mathrm{~mm}$ and a transition radius of $\mathrm{R}=0.2 \mathrm{~mm}$, achieving the values of reduced stresses 180 and $276.3 \mathrm{MPa}$, respectively. Therefore, the safety coefficients relative to the

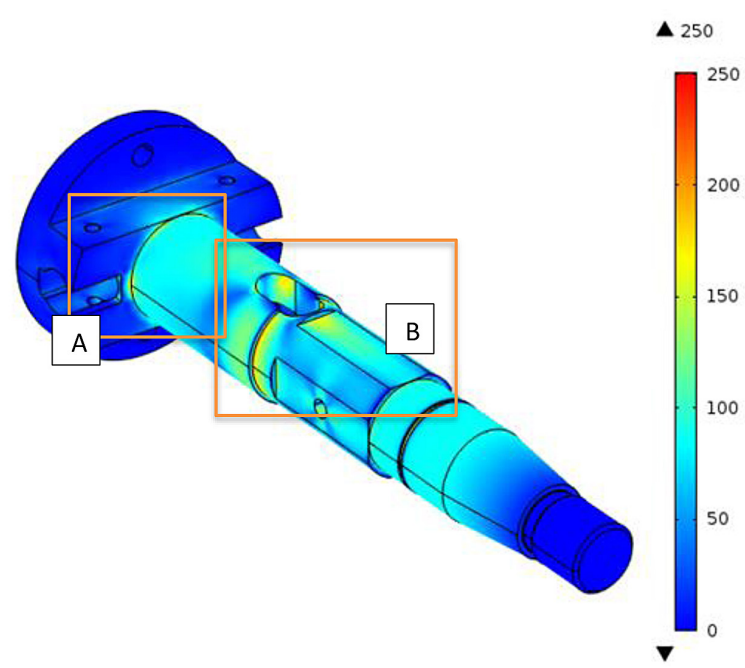

Fig. 3. The shaft loaded with a $300 \mathrm{Nm}$ torque stresses reduced $\mathrm{MPa}$ 


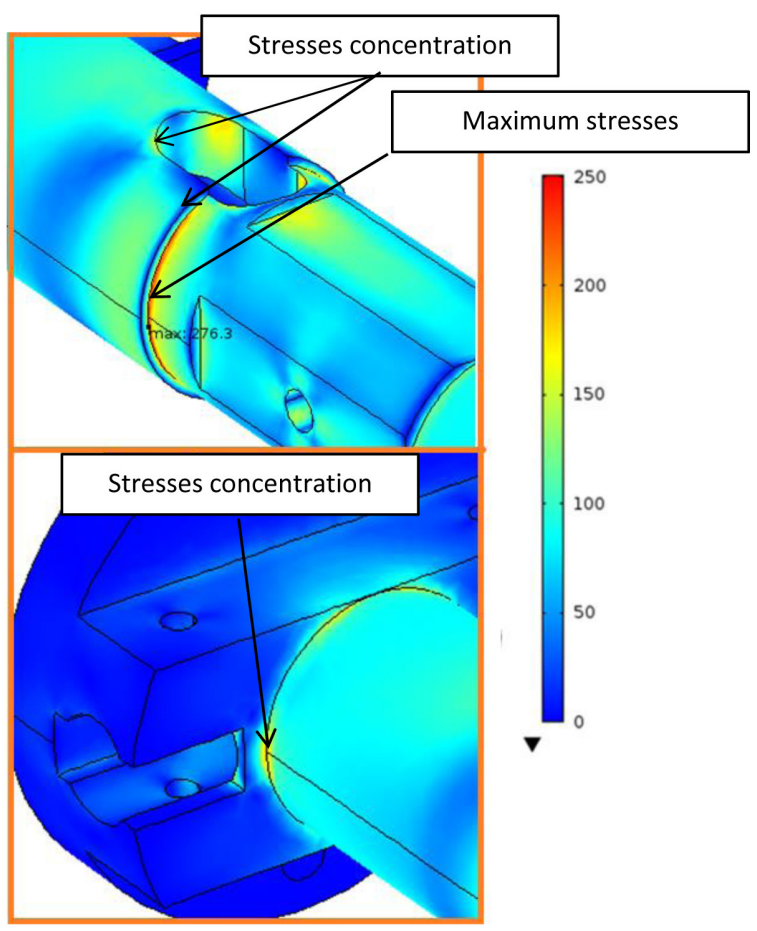

Fig. 4. Areas of stresses concentration $-\mathrm{MPa}$

yield point will assume the value of $\mathrm{xp}=1.77$ and 1.17. Taking into consideration fatigue cracks, the second case where crack initiation may occur is especially dangerous $[3,4]$.

Due to the local nature of the stress concentration, the submodel was analyzed, which is shown in Figure 4. It allows for an analysis of stress concentration from B area. This simplification will not significantly affect the stress value in zone B but will definitely shorten the calculation time.

In order to verify the stress values for the submodel, numerical calculations were made for the shaft loaded with the same torque as before, i.e. $300 \mathrm{Nm}$. The results of the simulation are presented in Figure 7 and Figure 9. The maximum stresses occur in the same plane and section and

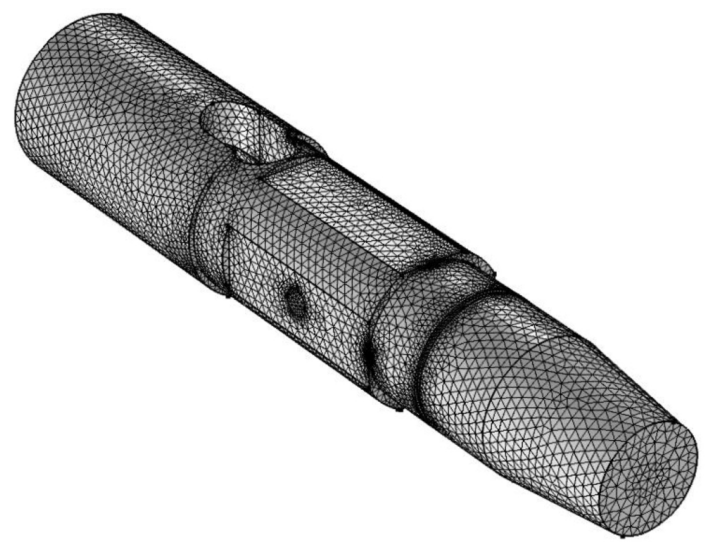

Fig. 6. The grid of finite elements

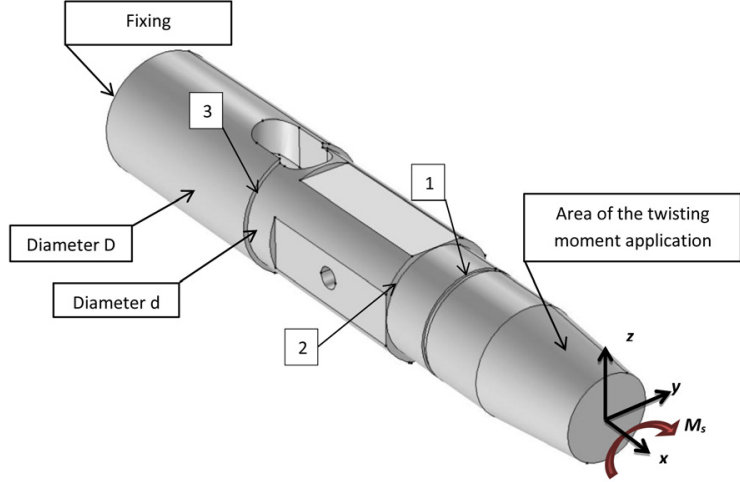

Fig. 5. The simplified model

reach the value of $273 \mathrm{MPa}$, which is only $1.1 \%$ less than before. It means that the applied simplification of the model will not significantly impact the simulation results.

In order to minimize the concentration of stresses at the shaft offset shoulders, several versions of transitions between nodes No. 1, 2 and 3 were analyzed. In order to do a correct analysis of the areas of stress concentration, the shaft was analyzed in several cross-sections, Fig. 9, Fig. 10, and Figure 11. At first, the simplest technological solution was chosen, i.e. making transitions with the appropriate radius of rounding. Edge rounding has been applied in node no. 3 with the radius $\mathrm{R}=1 \mathrm{~mm}$ (Fig. 8) and $\mathrm{R}=2 \mathrm{~mm}$. In the first case, the maximum stresses reached $219 \mathrm{MPa}$ so they were decreased by almost $20 \%$ compared to the previous value. With further increase of

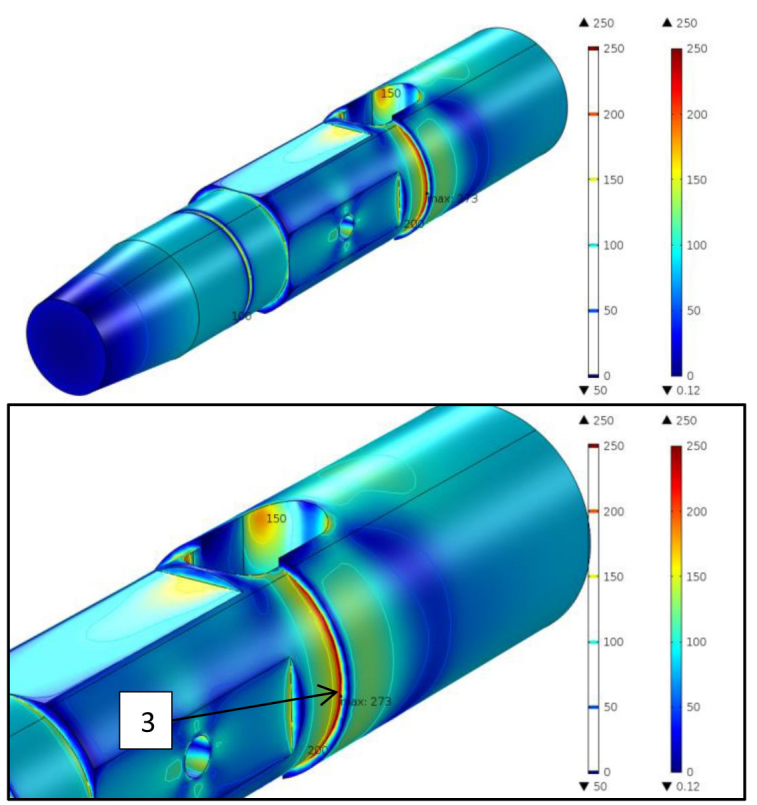

Fig. 7. Maximum stresses in node no. $3(\mathrm{MPa})$ for the submodel 


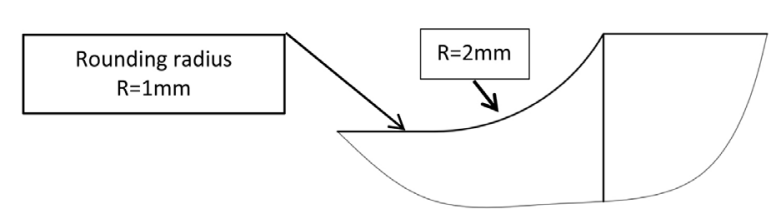

Fig. 8. Technological undercutting in node no.3-radius $\mathrm{R}=2 \mathrm{~mm}$

the rounding radius to the value of $\mathrm{R}=2 \mathrm{~mm}$, (Fig. 8) it was possible to lower the stresses at the transition from diameter $\mathrm{D}$ to $\mathrm{d}$ in the node No. 3 to $188 \mathrm{MPa}$ (Fig. 10). However, the maximum stresses $(210 \mathrm{MPa})$ appeared in the through groove (Fig. 9), which clearly shows the mutual interaction between notches.

Therefore, due to the interaction between notches in node No. 3, an attempt was made to change the shape of the technological gap. The gap proposed by Grodziński [2] was used, as in Fig. 11. The shape change of the gap caused a further decrease in stresses to the value of $184 \mathrm{MPa}$, (fig. 14), however, it contributed to the further increase of stresses in the groove to the value of $241 \mathrm{MPa}$ (Fig. 12, 13).

On the other hand application of the ellipse technological undercutting in node no. 3 with a radii ratio of 2:1 enabled further reduction of stresses in the notch (Fig. 15). However, there was a further increase in the maximum stresses, as shown in Figures 16 and 17.

When further modifying the shape in node No. 3 and using the machining undercutting as per the shape proposed by Mattheck [6] (Fig. 18), it is possible to further reduce the stresses in the notch itself with a slight increase in the cutout. Figure 20 presents a comparison of the proposed shapes of technological undercutting in node No. 3. The use of curvilinear shapes in (Fig. 21,

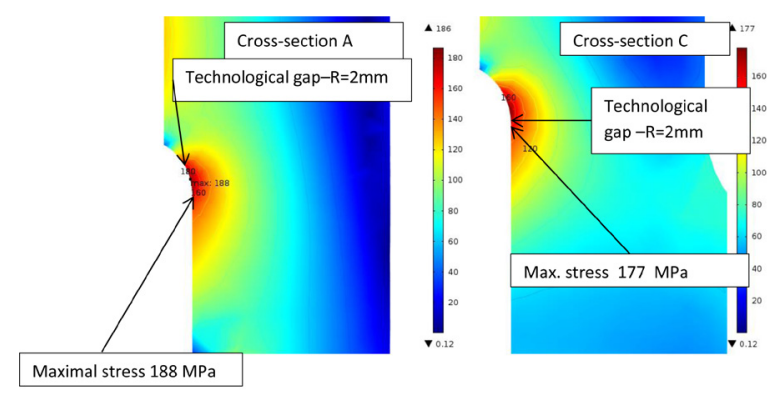

Fig. 10. Concentration of stresses in section A and C in node 3 for technological undercutting with radius $\mathrm{R}=2 \mathrm{~mm}$

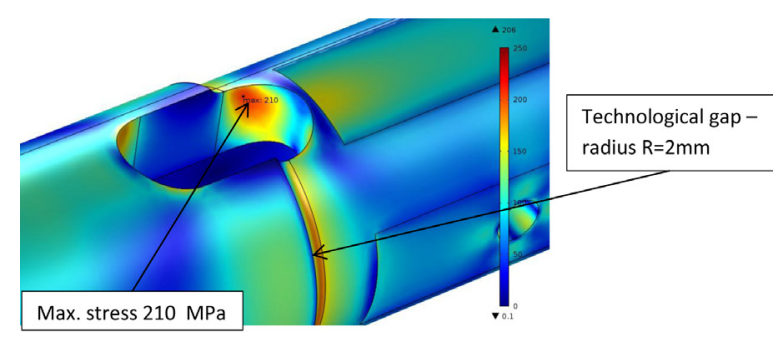

Fig. 9. Areas of maximum stresses

23) and an ellipse is much more difficult compared to a radial undercut but now, thanks to the use of CNC machine tools, it is feasible.

The numerical tests clearly showed that application of the machining gap made according to the shape proposed by Mattheck [6] allowed for the reduction of maximum stress in the notch in node No. 3 from the initial value of $273 \mathrm{MPa}$ to $164 \mathrm{MPa}$, i.e. (Fig. 20) by nearly $40 \%$. However, due to the occurrence of the coupling between the notch in node No. 3 and the notch resulting from the bean cutout, there was no significant drop in the maximum stresses. They decreased from 273 to $250 \mathrm{MPa}$ (Fig. 17), a drop of only $8 \%$. Therefore, it is suggested that removal of the bean cutout from the technological gap in node No. 3 be considered, if possible. This will reduce the coupling between these notches, and will thus most likely reduce the maximum stresses. Further analyses included stress concentration testing in nodes No. 1 and No. 2. Due to the node no. 1 dimensions, radial undercutting were used (Fig. 22). There were tested radii $\mathrm{R}=0.3 \mathrm{~mm}$ and $\mathrm{R}=0.5 \mathrm{~mm}$. (Tested two: $\mathrm{R}=0,3 \mathrm{~mm}$ and $\mathrm{R}=0,5 \mathrm{~mm}$ ). In turn, in node No. 2 a normalized undercut type C (Fig. 23, 24) [9] was used, which according to the research presented in [1] allows for the greatest reduction in stress concentration (Fig. 26, 27).

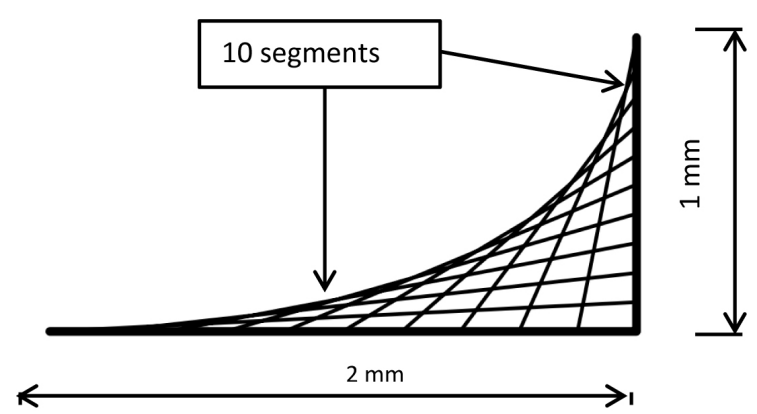

Fig. 11. Technological undercutting no $3[2,10]$ 


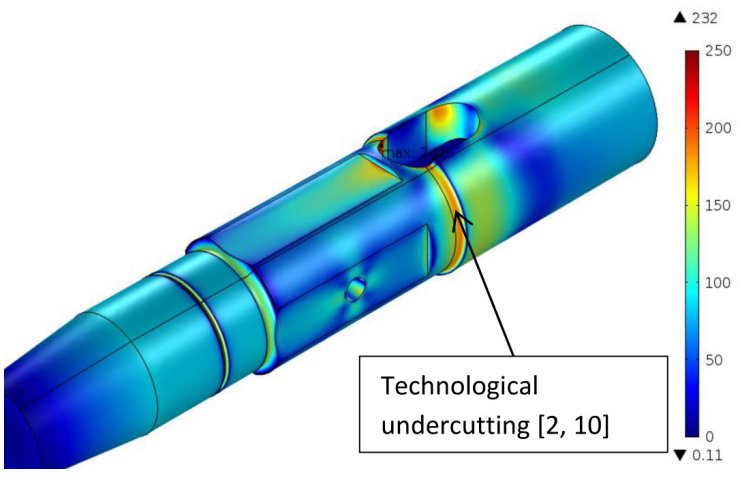

Fig. 12. Reduced tension

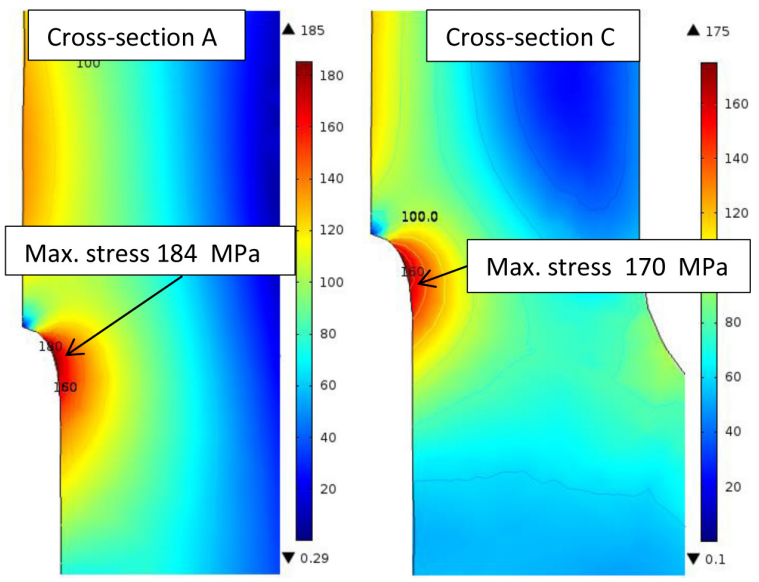

Fig. 14. Stress concentration in node No. 3 for technological undercutting $[2,10]$

\section{EXPERIMENTAL VERIFICATION}

In order to verify the results of the theoretical tests, experimental tests were performed on the shaft. They included assessing the strength of the shaft with a static load torque. They were done at the station, a diagram of which is shown in Figure 28. In this solution, the shaft tested no. 3 is mounted in roller bearings and fixed to the ground 4 at one end. The torque loading the shaft is introduced through the coupling 2 . This moment is

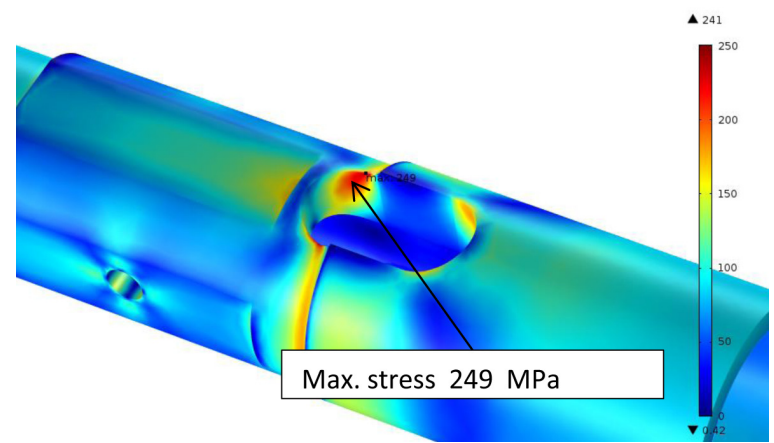

Fig. 16. Location of maximum stresses for technological undercutting in node no.3 - ellipse 2:1

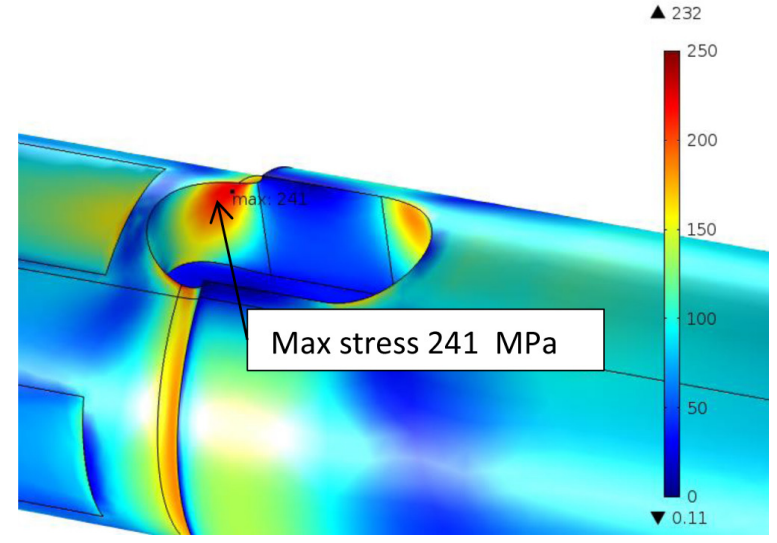

Fig. 13. Location of maximum stresses for technological undercutting $[2,10]$

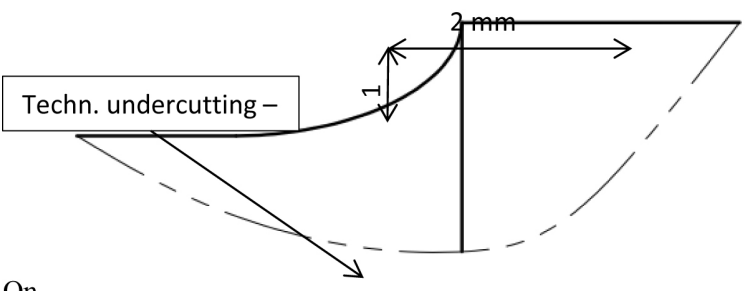

Fig. 15. Technological undercutting no 3-ellipse 2:1

caused by the force $\mathrm{F}$ acting on the arm $\mathrm{L}$ on the intermediate shaft 1 , whose bearings take over the transverse load. This solution protects the tested shaft against bending moment and transverse forces. The research was carried out, changing the force $\mathrm{F}$, and thus the twisting moment $\mathrm{M}_{\mathrm{s}}$. For the expected practical value of the shaft load $\mathrm{M}_{\mathrm{s}}$ $=300 \mathrm{Nm}$, the shaft did not show any permanent deformation, returning to the starting position after lightening. In order to evaluate its acceptable load, the moment value was increased until plastic deformation was observed. Noticeable permanent plastic deformation occurred at the moment
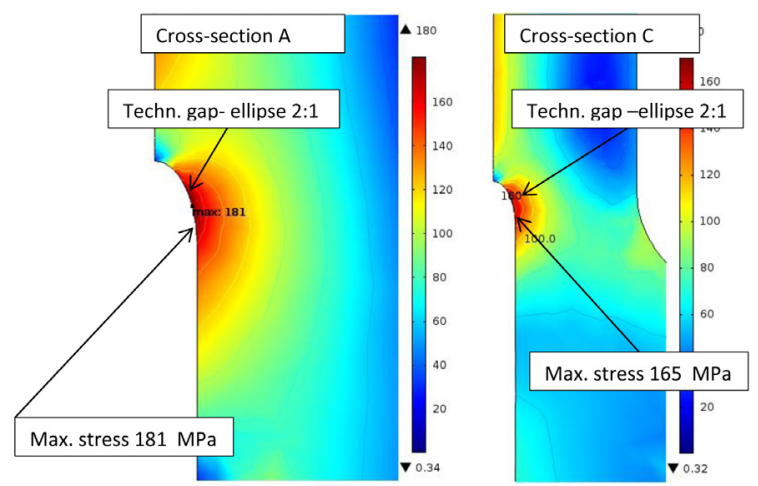

Fig. 17. Concentration of stresses in cross-section $\mathrm{A}$ and $\mathrm{C}$ in a node 3 for technological undercutting -ellipse 2:1 


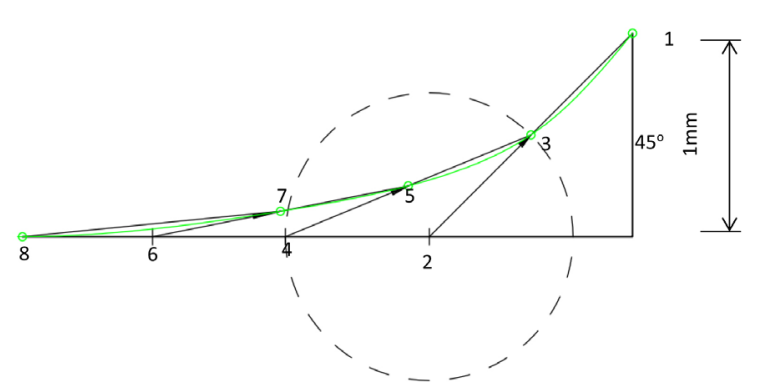

Fig. 18. Technological undercutting no 3 -construction [6]

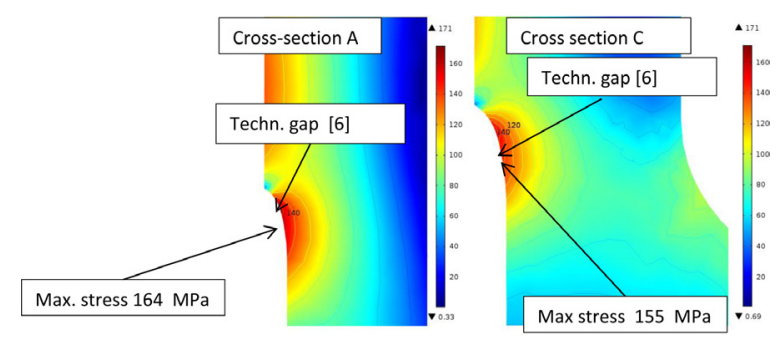

Fig. 20. Concentration of stresses in cross section A and $\mathrm{C}$ in a node 3 for technological undercutting [6]

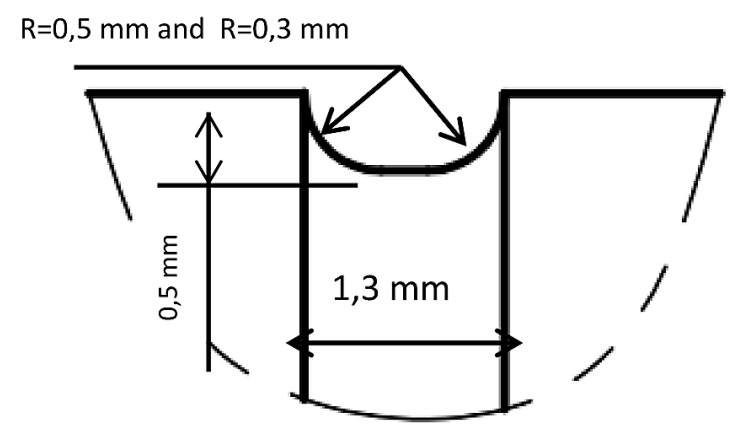

Fig. 22. Technological undercutting in a node no. 1 - dimensions

of loading $\mathrm{M}_{\mathrm{s}}=602 \mathrm{Nm}$, which according to the theoretical calculations, correspond with the reduced stresses equal to the yield point of the material, with the value of $325 \mathrm{MPa}$. Considering the function of the shaft in the injection pump, it can therefore be considered destroyed. The area of material flow is shown in Figure 29.

\section{CONCLUSIONS}

The drive shaft of the injection pump is one of its basic components. The shaft's strength and its torsional stiffness determine the proper functioning of the pump and ensure appropriate phases of fuel injection. The complexity of

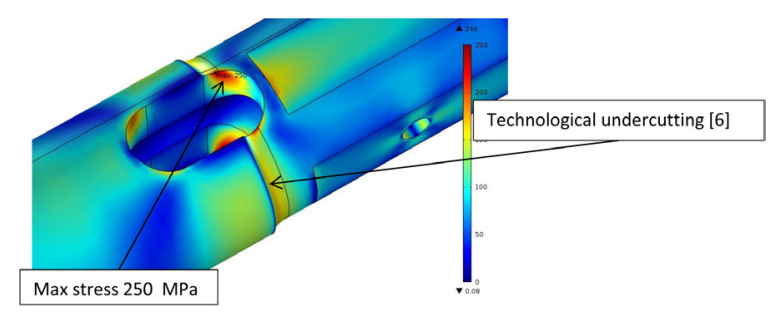

Fig. 19. Location of maximum stresses

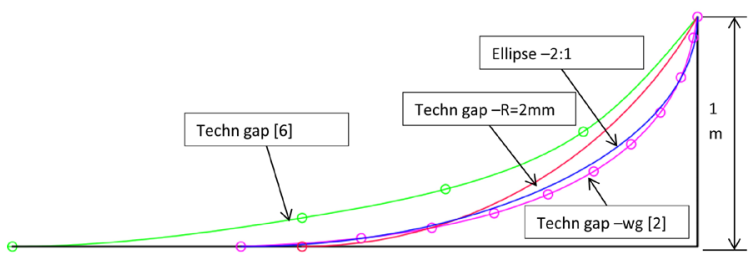

Fig. 21. Comparison of curvatures for different undercuts in node no. 3

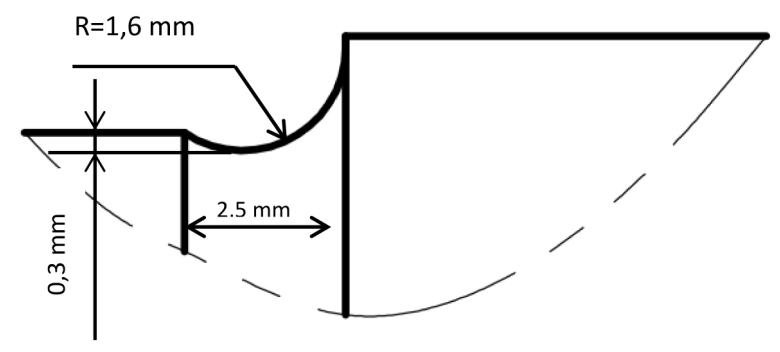

Fig. 23. Technological gap in a node no. 2 in figure 1- technological undercutting type C [9] (Table 1)

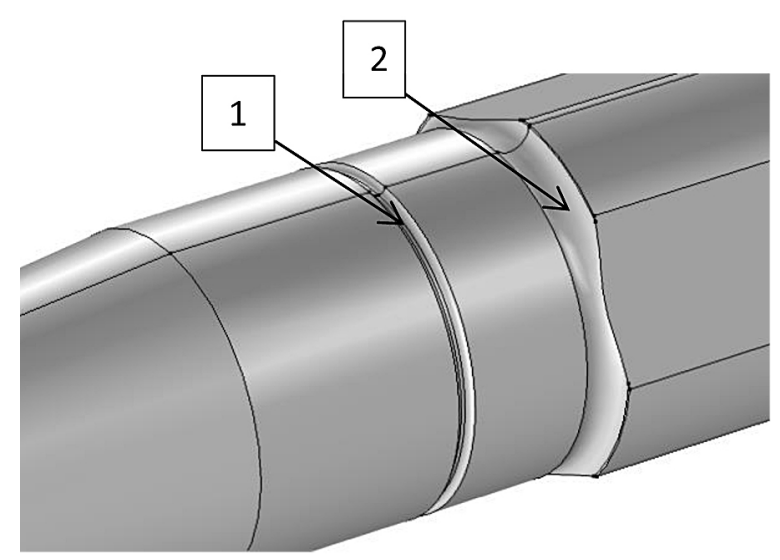

Fig. 24. Shaft view with technological gaps in nodes 1 and 2

the construction of the whole unit involves the appropriate shaping of the elements, including the shaft. In the considered case, a non-standard solution was introduced for reasons pertaining to the functioning of the pump, including a beanshaped hole, extending through the width of the entire shaft, which is a significant structural 


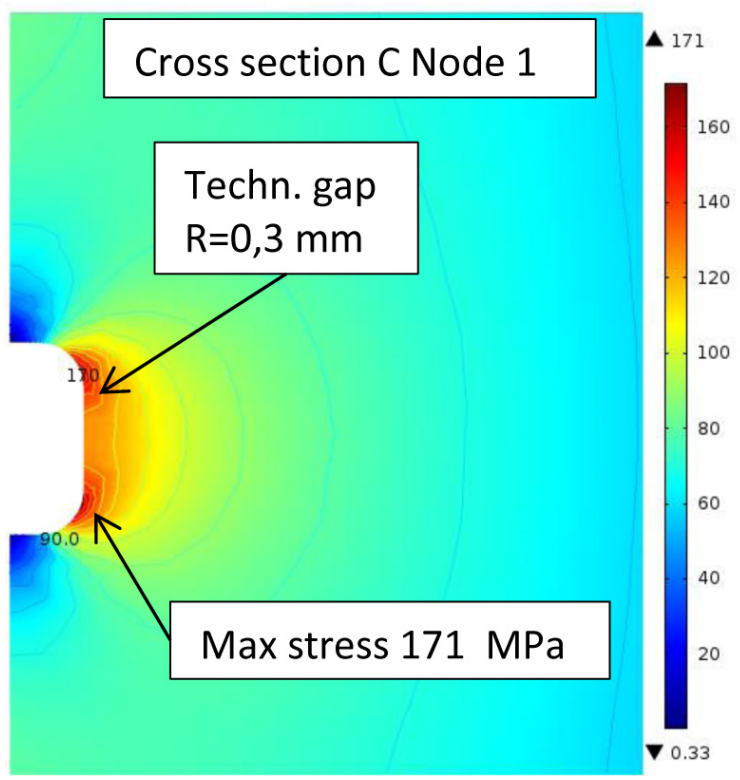

Fig. 25. Stress concentration in crossection $C$ in a node no 1

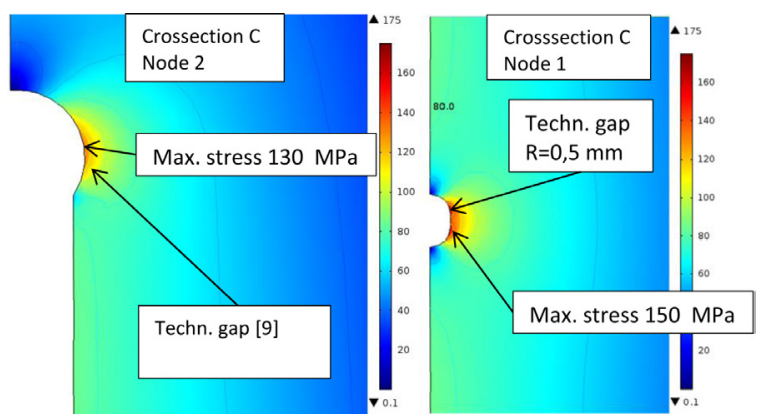

Fig. 27. Stress concentration in crossection $\mathrm{C}$ in nodes 1 and 2

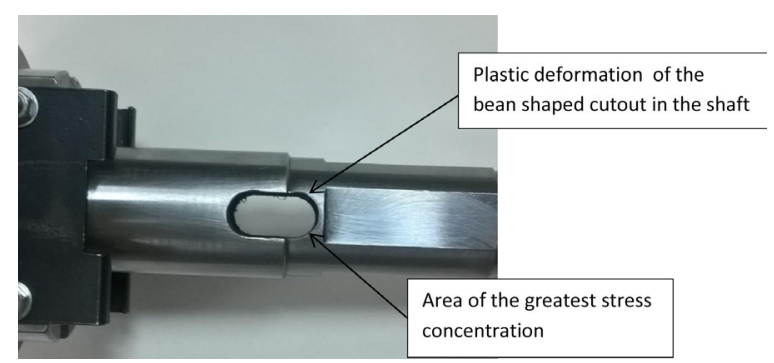

Fig. 29. Area of the greatest stress concentration in a pump shaft with a plastic deformation

notch not described in the shaft literature. The conducted theoretical studies confirmed very significant stress concentration (coefficient $\alpha_{\mathrm{k}}$ at the level of 2.63, according to [8] even 4.7), which may be the cause of fatigue cracks. The conducted operations consisting primarily of changes in transition radii of individual shaft stages (structurally acceptable) allowed to maintain adequate strength of the structure, resulting

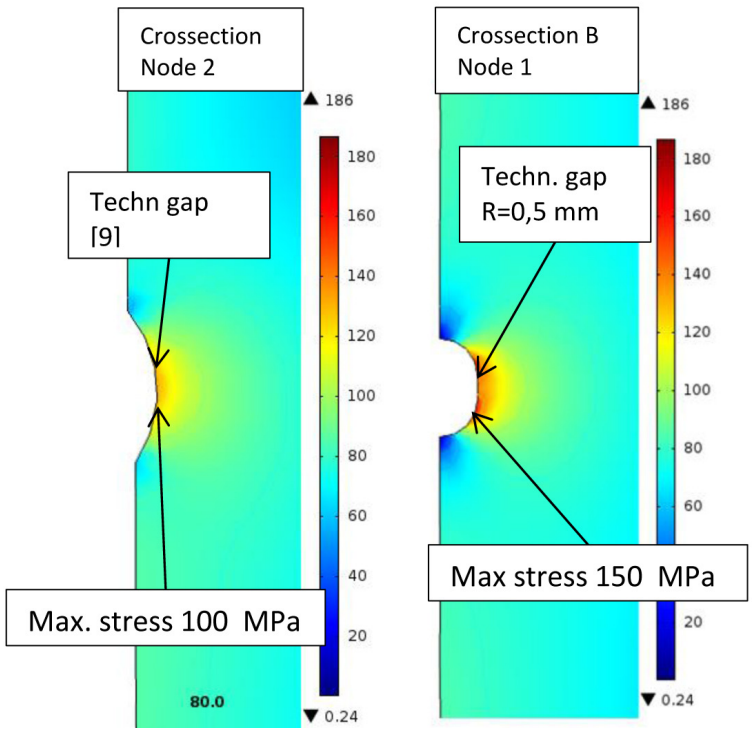

Fig. 26. Stress concentration in crossection B in nodes 1 and 2
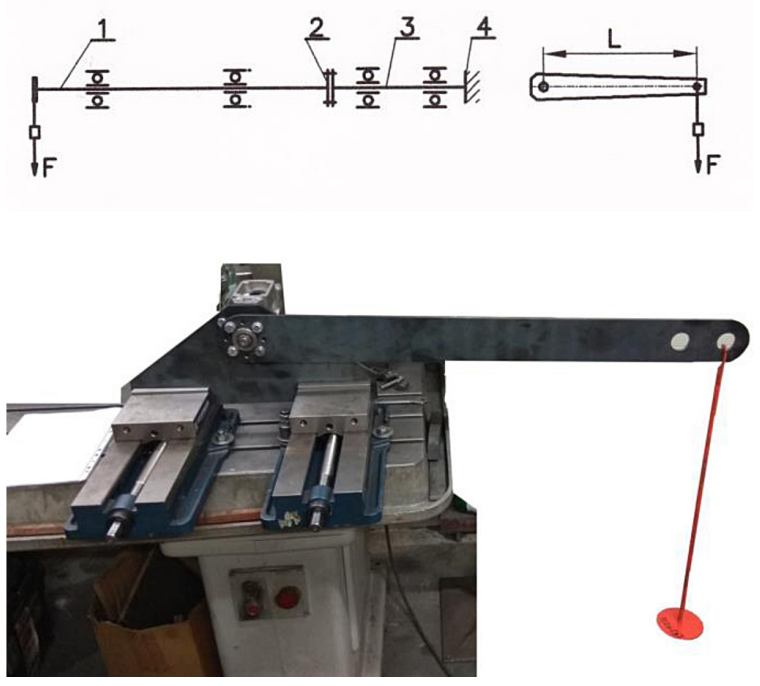

Fig. 28. Stand for the pump shaft testing : a) scheme of operation, b) appearance of the station: 1- auxiliary shaft, 2- coupling, 3 - tested shaft, 4 - fixing

in a safety factor at the level of $x_{p}=1.7$., which should be considered as a permissible value. The conducted experimental tests of the shaft confirmed the correctness of the adopted calculation model and design solution. Destruction of the structure took place at the value of the torque $\mathrm{M}_{\mathrm{s}}$ $=602 \mathrm{Nm}$, which is more than twice the maximum torque transmitted by the pump shaft under extreme conditions.

\section{Acknowledgements}

We would like to express our very great appreciation to ZPU Mirosław Pogoda for their 
valuable and constructive suggestions and technical support during the planning and development of this research work as well as conducting the experimental tests.

\section{REFERENCES}

1. Gotowała K., Patyk R., Patyk S.: Badania numeryczne wpływu rodzaju podcięcia obróbkowego wałka na jego wytrzymałość zmęczeniową. Autobusy, 6, 2015.

2. Grodziński P.: Investigation on shaft fillets. Engineering, 152, 1951, 321-324.

3. Kocańda S.: Zmęczeniowe pękanie metali. WNT Warszawa 1985.
4. Kocańda S., Szala J.: Podstawy obliczeń zmęczeniowych. PWN, Warszawa 1985.

5. Lisowski F.: Modelowanie MES struktur o karbach szeregowych. Czasop. Techniczne, 7, 2011, 341-348.

6. Mattheck C., Burkhardt S.: A new method of structural shape optimization based on biological growth. Int. J. Fatigue, 12(3), 1990, 185-190.

7. Peterson R.E.: Stress conventraction factors. Willey, New York 1974.

8. Pilkey W.D., Pilkey D.F.: Petersons's stress concentration factors. John Willey \& Sons Inc. 2008.

9. Podcięcia obróbkowe PN-58/M-02043, Polski Komitet Normalizacyjny.

10. Serensen S.V., Kogaev V.P., Snejderovic R.M.: Nesuscaja sposobnost i rascety detalej masin na procnost. Masinostroenie, Moskva 1975. 